\title{
Research on Key Core Technologies of Local Manufacturing Industry Assisted by Universities from the Perspective of Industry-University-Research Collaborative Innovation
}

\author{
Xiaomei Sun ${ }^{*}$
}

Department of Humanities and Social Sciences, Jiangsu University of Science and Technology, Zhenjiang, Jiangsu, China

${ }^{*}$ Corresponding author. Email: maysxm@foxmail.com

\begin{abstract}
As an important source of scientific and technological innovation, colleges and universities are the main force to help the local manufacturing industry to complete key core technology research. Building a technological innovation platform that combines production, education and research is an important measure for universities to help local manufacturing industries to tackle key core technologies. From the perspective of industry-university-research cooperation and collaborative innovation, to study the creation of scientific and technological innovation platforms in universities, it is necessary to implement the development concept of "pro-" enterprises. Universities are the technical support and source of innovation for enterprises, and the needs of enterprises are the driving force for technological innovation in universities. School-enterprise alliance builds a technology research and development system that closely integrates production, education and research, and carry out key core technology research.
\end{abstract}

Keywords: Industry-university-research collaborative innovation, Science and technology innovation platform, Key core technology research.

\section{产学研协同创新视域下的高校助力地方制造业关键核 心技术攻关研究}

\author{
孙小梅*
}

江苏科技大学人文社科处，江苏镇江，中国

*通讯作者.邮箱: maysxm@foxmail.com

中文摘要

高校作为科技创新的重要动力源, 是助力地方制造业关键核心技术攻关的主力军。构建产学研相结合的科技创 新平台是高校助力地方制造业关键核心技术攻关的重要举措。从产学研合作协同创新视域下，研究高校科技创 新平台的创建，必须推行“亲”企业的发展理念，高校是企业创新的技术支持和创新源头，企业的需求是高校技 术创新的原动力, 校企联合, 构建产学研紧密结合的技术研发体系, 开展关键核心技术攻关。

关键词：产学研协同创新，科技创新平台，关键核心技术攻关 


\section{1. 引言}

制造业是国民经济的支柱产业, 是一个国家综合 实力、创造力和竞争力的重要体现。习近平总书记在 党的十九大报告中指出, 坚持和发展中国特色社会主 义, 总任务是实现社会主义现代化和中华民族伟大复 兴。工业化是现代化的基础和前提，制造业是推动工 业化和现代化的主力军。具有自主知识产权的关键核 心技术，则是企业的“命门”所在。制造业企业必须在 关键核心技术上不断实现突破, 在关键领域实现自主 可控, 才能掌握产业发展的主动权。这一点在中美贸 易摩擦中最有体现, 由于美国政府的制裁, 中兴集团 的芯片供应商高通集团中止了对中兴的供货，这一决 定一度使中兴集团陷入困境, 不得不停产。这一事件 再次向我们警示了没有关键核心技术的危险。

关键核心技术是国之重器, 是企业核心竞争力、 区域产业系统和国家创新体系的重要支撑。持续提升 自主创新能力, 攻克关键核心技术, 已成为推动制造 业高质量发展的根本动力。这是一项系统工程, 需要 产学研深度融合, 吸引高校、科研院所参与协同创新, 突破创新主体间的壁垒, 充分释放各主体间“人才、 资本、信息、技术”等创新要素的活力, 有效汇聚创 新资源, 从而实现深度合作。产学研深度融合, 协同 创新, 实际上就是构建科技创新的社会网络化, 例如, 企业和地方高校通过组建跨学科学术团队、联合共建 研究平台、培育高新技术研究领域等开展一些协同创 新活动, 针对地方经济社会发展需求开展科技攻关等。

高校作为科技创新的重要动力源, 是助力地方制 造业关键核心技术攻关的主力军。开展产学研合作, 在高校、科研院所与产业之间建立互动链, 制造业企 业为技术需求方, 高校或科研院所为技术供给方, 企 业、高校与科研院所等按照“利益共享、风险共担、 优势互补、共同发展” 的原则, 以技术合约为基础相 互配合, 发挥各自优势, 形成强大的研究、开发、生 产一体化的平台, 并在运行过程中体现出综合优势。 高校是知识创新和传播的主要基地, 但对国家科技方 针导向的反应不够敏捷, 对生产企业科技需求缺乏及 时响应, 通过与生产企业建立科技合作联盟, 高校能 够直接参与科技知识和科技创新成果的创造。因此, 构建产学研相结合的科技创新平台是高校助力地方 制造业关键核心技术攻关的重要举措。

\section{2. 高校科技创新平台建设的研究现状}

当前, 关于高校科技创新平台建设的研究大多集 中在以下几方面, 比如, 在开展科技创新过程中, 高 校与高校之间、高校内部的院系之间、重点实验室之 间、甚至科研人员之间相对分散, 科学研究是个体进 行的独立研究, 科技资源和成果相互封锁。但是科技 创新是一项复杂、艰巨的群体劳动, 人们逐步认识到 了科研协作的重要性, 开始探讨如何实现高校内部科 技资源和人才资源的有效整合。如徐剑波等人在《论 高校科技创新平台的工作机制》(《科学管理研究》,
2009（2））一文中指出高校学科门类比较全面, 但 是没有实现各学科之间的融合交叉, 导致科研力量分 散, 不能有效共享学校的实验设备等, 因此, 应将高 校科技创新平台组建成一支融合多学科人才优势力 量的创新实体 ${ }^{[1]}$ 。王立剑等在《高校科技创新平台绩 效评价指标体系构建与应用》 (《科学学与科学技术 管理》，2010（2））一文中认为高校科技创新平台 包括设在学校的国家和省部级工程技术研究中心、国 家和省部级重点实验室以及学校自建的研究开发基 地等 ${ }^{[2]}$ 。曹蓓等在《构建高校科技创新平台的探索与 思考一以南方医科大学为例》 (《中国高校科技》, 2016（9））一文中提出构建起高水平的科技创新平 台, 以适应科技工作链条式发展需求 ${ }^{[3]}$ 。

实际上, 高校科技创新平台有效运行需要多主体 支撑，包括政府、高校、科研机构、企业、相关服务 行业等, 由政府倡导, 高校主导, 企业、科研院所紧 密合作, 金融机构和科技中介组织积极参与, 是高校 与社会资源合作开展科技创新, 组建科技研发战略联 盟。在有关高校科技创新平台建设的研究工作中, 不 能仅限于探讨高校内部资源的优化组合，而应该拓宽 思路, 从产学研合作的视角, 创建科技创新平台。目 前, 高等教育的功能已从人才培养、科学研究延伸到 社会服务, 通过产学研的紧密结合, 将高校创造的科 技创新成果尽快转化为产业优势, 助力地方制造业关 键核心技术攻关, 已经成为高校发展的一个重要命题。

自 20 世纪 80 年代开始, 国内学者对产学研合作 展开研究 ${ }^{[4]}$ 。1986 年, 原国家经贸委员会、国家教育 委员会及中国科学院提出了 “产学研”联合的主张。 1992 年, 由原国家经贸委、教育部、中国科学院共同 组织实施了“产学研联合开发工程”, 其宗旨是: 在建 立社会主义市场经济体制的过程中, 通过产学研联合, 建立企业与高等院校、科研院所之间密切而稳定的合 作关系, 逐步形成产、学、研共同发展的运行机制, 探索一条适合中国国情的科技与经济密切结合的道 路。从提出“产学研联合”思想至今, 历经近 40 年的 理论研究与实践探索, 我国在产学研合作研究上取得 了一定的成绩。在中国知网总库以“产学研合作”为关 键词进行“精确”检索（不限文献年份），共得到期刊 论文 4542 篇, 其中涉及社会科学领域和经济与管理 科学领域研究论文较多, 前者共计 2027 篇, 占 $44.6 \%$, 后者共计 2515 篇, 占 $55.4 \%$ 。在经济与管理科学领域 研究论文中, 根据主题类别大致又分为宏观经济管理 与可持续发展、经济体制改革、企业经济、工业经济、 科技管理研究等, 其文献主题的分布情况如下图 1 所 示, 整体来看, “产学研合作”在科技管理研究和企业 经济中被较多关注, 在科技管理研究中占 $26 \%$, 在企 业经济中占 29\%。 


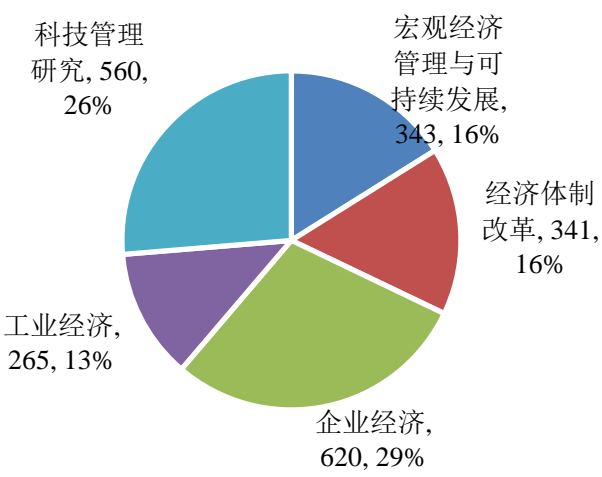

图 1 文献主题的分布情况图

但是同发达国家相比，我国对“产学研”合作的研 究还存在较大差距, 有待进一步提高和深化。在国外, 产学研合作开始较早、发展较好的国家是美国。威斯 康星州立大学在 20 世纪初就率先实施走出校门与社 会结合, 进行了历时十年的卓有成效的改革, 从而产 生了世界高等教育史上具有划时代意义的“威斯康星 思想”。“波士顿128号公路高技术园区”建立于20世纪 50 年代, 麻省理工学院通过产学研合作对该园区的建 设起到了摇篮的作用。斯坦福大学在1951年兴建了 “斯坦福研究园”, 该研究园的建立为全球最大的电子 工业基地“硅谷”奇迹般的崛起奠定了基础。日本也是 产学研合作开始较早的国家。日本经营团体联盟在 1956年发表了《关于适应新时代要求的技术教育的意 见》, 提出“要使理工系统的大学和产业界紧密地联 系起来, 大学方面要确切地把握产业界的要求” [5]。 此后, 日本政府便把产学研合作作为科技振兴和人才 培养的重大举措列入国家计划, 迈出了高校与企业的 产学研合作步伐。韩国的科技创新体系是官、产、学、 研联合研究体制, 即政府、企业、大学、科研机构相 互合作。此外, 欧盟各国也非常重视产学研合作的开 展 ${ }^{[6]}$ 。

由此可见, 国外较早开始探索通过产学研合作推 动科技创新, 注重对现有科技创新资源的整合。与国 外相比, 我国的科技创新资源更加有限和紧缺, 应当 采取措施优化现有科技创新资源的配置, 通过产学研 合作，建立科技创新平台，实现高校与企业科技创新 资源有效整合，提高高校科技创新能力。

\section{3. 产学研合作协同创新视域下的高校科技创 新平台建设}

高校集教育、科学研究和技术创新于一体, 是新 知识、新思想的重要发源地, 企业的技术创新活动离 不开高校的技术支持, 而企业的技术需求又是高校开 展技术创新的原动力, 没有企业的有效需求, 高校的 技术创新活动就会缺乏基础[7]。产学研合作, 协同创 新, 共建高校科技创新平台, 既解决了企业研发能力 不足问题, 也解决了科研和生产相脱节问题, 加快高 校科技成果向生产转化的进程, 充分发挥高校在地方 区域行业发展中的引领作用。

\section{1. 产学研合作创建高校科技创新平台, 必须 推行“亲”企业的发展理念}

我们从产学研合作视角出发, 创建高校科技创新 平台, 必须推行“亲”企业的发展理念, 一方面使高校 能够根据需要制定相关的规划和政策, 认真整合学校 的人才资源与科技资源, 确定具体的科学研究和成果 转化项目, 使科研成果尽快转化, 产生经济效益和社 会效益; 另一方面, 企业通过和高校合作, 集聚大量 的优秀科技人才，提升自身科技研发和自主创新能力， 为自身发展夯实基础; 此外, 通过高校与企业的共同 努力, 整合双方优势资源, 为高校和企业提供一个公 共、有效的发展空间, 高校整合企业研究力量, 以企 业不断更新的技术要求和强大的资金支持为后盾, 提 高高校的研发能力和创新效率, 企业将高校的人才、 科技优势和自身需求结合起来，进而提升自身的科技 创新能力。

高校通过产学研合作创建科技创新平台, 走“亲” 企业的发展路线, 主要从两个方面着手, 一方面, 高 校及时掌握企业发展中遇到的新问题及行业发展的 最新动向, 积极捕捉企业的技术需求, 使企业的需求 与高校的科学研究工作紧密结合起来, 使高校科研工 作更好地为企业生产服务; 另一方面, 高校发挥多学 科优势, 进行知识创新活动, 开展前瞻性的技术研究, 攻克核心技术，占领科学制高点，努力为企业十年、 二十年之后的产品升级换代提供技术支撑。这样才能 从根本上发挥好高校的作用, 使高校和企业建立稳定 的合作关系。而企业是市场需求和动向的风向标, 应 及时向高校提出技术需求, 发起创建科技创新平台, 与高校建立长期合作关系, 把高校的科研创新成果及 时进行市场转化, 使高校科研成果尽早为经济社会发 展服务。

\section{2. 产学研合作创建高校科技创新平台, 有利 于建立产学研紧密结合的技术研发体系}

我们从产学研合作视角出发, 创建高校科技创新 平台, 形成产学研联盟, 高校在广泛参与科技成果转 化和产业化过程中, 积极参与行业和企业的技术开发, 有利于逐步形成以推动各行各业技术进步为主要目 标的技术转移和服务体系。

目前, 高校面向企业和社会需求, 建立大学技术 转移中心和科技服务中心, 形成产学研紧密结合的技 术研发体系, 归纳起来有以下五种典型的形式。

\subsection{1. 依托大学科技园}

大学科技园是国家科技创新体系的重要组成部分, 其构成主要是依托具有较强科研实力的高校, 把高校 的综合智力资源优势与其它社会优势资源相结合, 搭 建科技协同创新平台。大学科技园可以充分利用高校 的人才智力优势, 为高校科技成果转化、高新技术企 
业捊化、创新创业人才培养、产学研用结合提供支撑 平台和服务机构。

\subsection{2. 与企业共建研发机构}

高校与企业共同组建联合实验室、教学实验示范 中心、工程技术中心等研究机构, 借助共建研究机构 这样一个平台, 企业可以有针对性的对高校相关技术 领域的科研创新进行持续投入，储备技术和人才; 同 时，有企业提供的科研基金和技术需求做支撑，高校 可以持续开展针对某一专业领域核心关键技术的攻 关, 保证科研工作的连续性, 实现科研工作的实用性 与实效性。

\subsection{3. 在中心城市建研究院}

在当今知识经济时代, 高校已成为推动经济社会 发展的重要动力, 高校和地方的科技经济发展已融为 一体, 借助研究院, 高校捕捉地方经济发展的热点问 题, 针对地方主导产业中的共性技术和关键技术开展 研究, 解决产业和行业的关键核心技术难题, 从而推 动产业升级。

\subsection{4. 组建学科性公司}

高校整合自身的科研成果和人才优势, 创办具有 “知识创造”能力的集科研、生产、创新人才培养于一 体的经济实体, 主要任务是尽快将科研成果孵化为成 熟的技术并形成产品, 投入应用或生产, 实现科技成 果向现实生产力的快速转化, 实现人才培养、科研发 展与经营效益并举。

\subsection{5. 与企业共建经济实体}

鉴于校内组建公司资产薄弱, 高校可以尝试与校 外企业合作, 建立优势互补的产学研用长效合作机制, 利用经济杜杆把双方利益密切结合在一起, 形成经济 利益共同体。在具体实践中, 可成立股份制企业（集 团），学校以所开发的产品或技术（个别投入一定的 资金）占有股份，以董事会的形式参与管理; 也可以 是高校与企业联合承担工程研制任务, 以协议的方式 明确联合体领导成员、办事机构及合作内容, 具体合 作以合同方式约定。

从产学研合作的视角出发, 创建高校科技创新平 台, 在人、财、物上充分整合校企双方资源, 不仅有 助于高校改善科研条件, 提升科技创新能力, 更有利 于企业尤其是制造业, 将先进的科学技术迅速转化为 生产力, 助力关键核心技术攻关。

\section{致谢}

本研究成果由江苏省社会科学基金项目 （20GLD006）资助支持完成。

\section{REFERENCES}

[1] Xu Jianbo, Su Yuezeng. The Discussion on Working Mechanism of the Scientific and Technological Innovation Platform of Colleges and Universities, [J]. Scientific Management Research, 2009, 27(01): 22-25.

[2] WANG Lijian, LIU Jia. Positive Analysis and Construction of Evaluation Index of the Scientific and Technological Innovation Platform of Colleges and Universities [J]. Science of Science and Science and Technology Management, 2010, 31(02): 110$112+123$.

[3] Cao Bei, Zhao Xingcun, Zhao Zhen. Exploration and thinking on constructing a scientific and technological innovation platform in colleges and universities__ Taking Southern Medical University as an example [J]. Chinese University Science and Technology ,2016(09): 23-24.

[4] Miao Su-lian. A Study of Production-teaching -research Cooperation: Problems and Counter measures[J]. Journal of Guangdong University of Technology (Social Science Edition), 2010, 10(05): 44-47.

[5] Xu Jin, Cai Zexiang. The Comparison and Reference of the Cooperation Model of Production, Teaching and Research in Foreign Universities [J]. Finance Teaching and Research, 2008(01): 63-66.

[6] Andersen P D, Andersen A D, Jensen P A, et al. Sectoral innovation system foresight in practice: Nordic facilities management foresight[J]. Futures, 2014, 61: 33-44.

[7] Kou M, Chen K, Wang S, et al. Measuring efficiencies of multi-period and multi-division systems associated with DEA: An application to OECD countries' national innovation systems[J]. Expert Systems with Applications, 2016, 46: 494-510. 